\title{
Numerical analysis of the improving thermal energy efficiency of Taylor-Couette flow
}

\author{
KhaOUla Ben ABDELMLEK ${ }^{1}$, FAYÇAL BEN NEJMA ${ }^{1}$ \\ ${ }^{1}$ Research Unit of ionized and reactif media, \\ Rue Ibn Eljazzar, 5019 Monastir \\ TUNISIA
}

\begin{abstract}
This paper deals with adimensionnal analysis of natural convection in a horizontal cylindrical annulus. The inner cylinder is isothermally heated and rotates with an angular velocity $\Omega$, however the outer one is kept cold and motionless. The gap between cylinders is defined by an adimensional radius ratio $f$. The numerical study was carried out using COMSOL Multiphysics. The effects of Rayleigh number ranging from $10_{2}$ to $10_{6}$, radius ratio and rotation velocity on the flow pattern and the thermal behavior in the annulus are then elaborated. Particular attention is paid to the effect of different parameters on the local Nusselt numbers on the inner and outer cylinders, the mean Nusselt number and the energy efficiency of the process. Results show that the mean Nusselt number increases with the increase of Rayleigh number. However, it decreases with the increase of the radius ratio $f$ because of the narrowing of the annulus. The results prove also that the heat transfer rate drops with the rise of rotation velocity. Finally, it was found that the energy efficiency achieved its maximum for lower Rayleigh numbers $\mathrm{Ra}=10_{3}$, and lower rotation velocities.
\end{abstract}

Keywords-Taylor Couette flow, Natural convection, Energy efficiency.

Received: August 21, 2020. Revised: November 21, 2021. Accepted: November 30, 2021.

Published: December 4, 2020.

\section{Introduction}

$\mathrm{F}$ or several years, Taylor-Couette flow presents not only a typical academic research topic, but also a challenge to general applications. In fact, the configuration is mainly composed of two coaxial cylinders. The inner one is rotating while the outer cylinder is fixed. It is found in many engineering applications, for example, centrifugal pumps, power stations alternators, turbines, wastewater purification systems, heat exchangers, turbomachinery and jets. The need to improve the efficiency of turbomachines has led to a need to understand the thermal and dynamic behavior of the TaylorCouette flow. Despite of the simplicity of the geometry, the exploration of the Taylor-Couette system continues to attract the attention of researchers since it is the unique outcome of centrifugal instabilities resulting from the rotation of the inner cylinder. In this context, several experimental and numerical research works have been developed in this subject since many decades [1-3] for the case of motionless cylinders. Powe et al [4-5] determined experimentally, for different radius ratios, the maximum value of Rayleigh number for which the flow remains steady. Kuehn et al [6] studied both experimentally and numerically the same problem within air and water. The authors measured the temperature distributions and the local heat transfer coefficients, and they discovered that the critical Rayleigh number depends widely on the Prandtl number of the fluid under consideration. Then, in their later numerical work, Kuehn et al [7] studied the effect of the Prandtl number and the radius ratios on the heat transfer rate. The steady natural convection between cylindrical annulus was thereafter studied for low Prandtl numbers by Custer et al and Yoo et al [8-9]. Mojtabi et al [10] treated numerically the effect of radius ratios for two different Prandtl numbers $(\mathrm{Pr}=0.7$ and $\mathrm{Pr}=0.02)$. Later, Jischke et al [11] studied numerically the flow pattern in the annulus space. They showed that there is an ascending thermal plume above the inner cylinder; boundary layers are developed near the inner and the outer cylinders, and a stagnant region below the inner cylinder. Yan et al [12] studied numerically and experimentally the effect of radius ratios on the thermal and dynamic behavior in the annulus. They showed that in narrow annulus, the unicellular flow pattern changes into multicellular flow pattern when the Rayleigh number exceeds a critical value. In addition, for high Rayleigh number, an oscillatory flow pattern appears. However the oscillation has no effect on the mean Nusselt numbers of the inner and outer cylinder since the oscillation is restricted to a limited part of the annulus.

The turbulent natural convection has been also the subject of several numerical studies such as the work of Farouk et al [13] in which the authors applied the $\mathrm{k}-\varepsilon$ turbulence model to investigate the case of high Rayleigh numbers. However, Grossmann et al [14] treated the case of high Reynolds numbers in order to study the effect of turbulence on the Taylor-Couette system. Other works have been focused on the bifurcative natural convection and the stability of the fluid flow in the annulus [15-16]. 
Heat transfer in a horizontal rotating annulus with thermal driven flows was likewise numerically studied by Lee et al [17-18]. They supposed that the inner cylinder is rotating and considered the case of concentric and eccentric cylinders. Their numerical results showed that the mean Nusselt number increases with the increase of Rayleigh number for different positions studied. However, for a fixed Rayleigh number, the mean Nusselt number decreases throughout the flow. Tzeng [19] showed in his experimental study that the heat transfer coefficient increases with the increase of the rotational Reynolds number.

Numerical researchs are recently directed to study effects of heat flux boundary conditions [20-21], variable fluid properties (such as the viscosity and the thermal conductivity), thermal radiation [22-23] and mixed convection on the convective heat transfer in the couette flow vertical channel [24-25].

To our best knowledge, the heat transfer in cylindrical annulus is an old subject. But the energy efficiency of the process has not been adequately investigated. Therefore, in this present work, natural convection in horizontal cylindrical annulus is investigated. The inner cylinder is rotating; however the outer one is motionless. We propose to study the effect of Rayleigh number, the radius ratio and the angular velocity on the flow pattern and the thermal behavior in the annulus. Moreover, special attention is given to the heat transfer rate and the energy efficiency as a function of different parameters studied.

\section{Mathematical Modeling}

\subsection{Problem Formulation}

The schematic description of the physical problem is illustrated in Fig.1. It consists of two horizontal coaxial cylinders. The inner one is maintained at hot temperature $T_{h}$, and rotates at an angular velocity $\Omega$. The outer cylinder is considered motionless and kept at cold temperature $T_{c}$. The gap between the cylinders is filled with fluid.

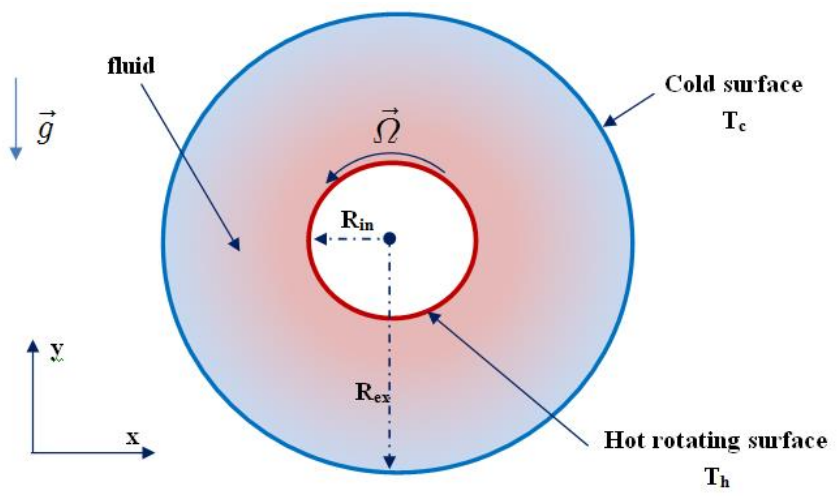

Figure 1 Schematic geometry of the problem

\subsection{Assumptions and governing equations}

The following assumptions have been made:

- The cylinders are infinite enough in length. So, we can consider that the flow and the heat transfer are bidirectional.
- The flow field is steady, Newtonian, incompressible and laminar with no-slip boundary conditions.

- The heat transfer by radiation is neglected

- The Prandtl number is assumed to be equal to 0.71

Based on these assumptions, the non-dimensional governing equations can be described in Cartesian coordinates as follows: The continuity equation:

$\frac{\partial U}{\partial X}+\frac{\partial V}{\partial Y}=0$

The momentum equations:

$U \frac{\partial U}{\partial X}+V \frac{\partial U}{\partial Y}=-\frac{\partial \Pi}{\partial X}+\mathrm{P}_{r}\left[\frac{\partial^{2} U}{\partial X^{2}}+\frac{\partial^{2} U}{\partial Y^{2}}\right]$

$U \frac{\partial V}{\partial X}+V \frac{\partial V}{\partial Y}=-\frac{\partial \Pi}{\partial Y}+\mathrm{P}_{r}\left[\frac{\partial^{2} V}{\partial X^{2}}+\frac{\partial^{2} V}{\partial Y^{2}}\right]+\mathrm{P}_{r} R_{a} \Theta$

The energy equation:

$U \frac{\partial \theta}{\partial X}+V \frac{\partial \theta}{\partial Y}=\left[\frac{\partial^{2} \theta}{\partial X^{2}}+\frac{\partial^{2} \theta}{\partial Y^{2}}\right]$

The non-dimensional variables used in the above equations are defined as follows:

$$
\begin{gathered}
X=\frac{x}{R_{\text {ext }}} ; Y=\frac{y}{R_{\text {ext }}} ; r=\sqrt{X^{2}+Y^{2}} ; U=\frac{u R_{\text {ext }}}{\alpha} ; V=\frac{v R_{\text {ext }}}{\alpha} ; W=\frac{\Omega R_{\text {ext }}^{2}}{\alpha} \\
\Theta=\frac{T-T_{c}}{T_{h}-T_{c}} ; \Pi=\frac{P R_{\text {ext }}^{2}}{\rho \alpha^{2}} ; \mathrm{P}_{r}=\frac{v}{\alpha} ; R_{a}=\frac{g \beta}{v \alpha} R_{\text {ext }}^{3} \Delta T ; f=\frac{R_{\text {ent }}}{R_{\text {ext }}}
\end{gathered}
$$

The heat transfer rate on the inner and outer cylinder can be measured in terms of local Nusselt number using the following expression

$N u_{\text {-int, ext }}(\phi)=2(1-f)\left|\frac{\partial \theta}{\partial r}\right|_{r=(f ; 1) ; \phi} \mid$

The mean Nusselt number is calculated by averaging the local Nusselt number along the inner hot cylinder. Its expression is as follows:

$N u_{\text {int }}=\frac{1}{2 \pi} \int_{-\pi}^{\pi} N u_{- \text {int }}(\phi) d \phi$

The mean dimensionless temperature and velocity are calculated using the following equations:

$$
\begin{aligned}
& \Theta_{a}=\frac{1}{\pi\left(1-f^{2}\right)} \int_{0}^{2 \pi} \int_{f}^{1} \Theta r d r d \phi \\
& U_{a}=\frac{1}{\pi\left(1-f^{2}\right)} \int_{0}^{2 \pi} \int_{f}^{1} \sqrt{U^{2}+V^{2}} r d r d \phi
\end{aligned}
$$

Finally, in order to evaluate the efficiency of the heating process, we define the expression of the energy efficiency as the ratio between the average temperature and the heat flux necessary to maintain this temperature (Eq.9). In this heating case, we seek its maximum.

$\varepsilon=\frac{\theta_{a}}{f \cdot N u_{\text {int }}}$

\subsection{Numerical procedure and validation}

The continuity, Navier Stokes and the energy equation are solved using the commercially available code COMSOL Multiphysics ${ }^{\circledR}$ based on the finite element method.

The grid dependency was investigated by changing the number of the triangular element meshes. Then, the number of the reference mesh was set to 21830 domain elements and 520 boundary elements as illustrated in Fig.2. The generating mesh 
was refined near the walls where the temperature gradients seem to be higher.

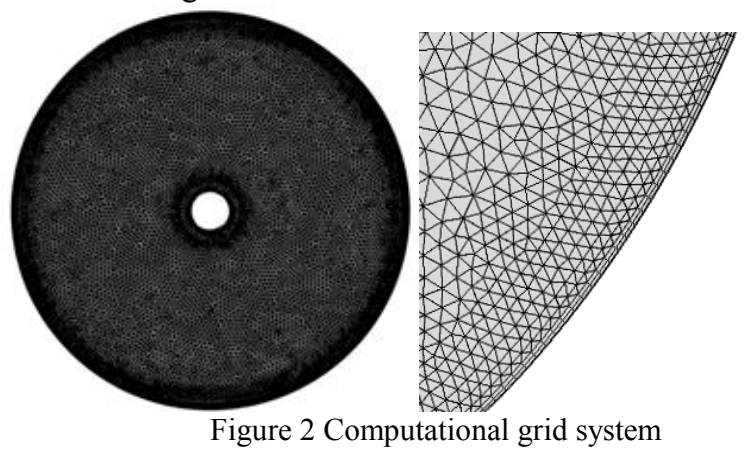

To check the validity of the proposed model, we compared our numerical results with those of Desrayaud et al [25] for the case of horizontal concentric annulus. The cylinders are differentially heated and considered immobile. Table.1 presents the comparison of the Nusselt number values on the inner cylinder. The error between our results and those of [25] is less than $2.5 \%$.

Table 1 Validation of the numerical model with literature

\begin{tabular}{|l|l|l|l|}
\hline $\mathrm{Ra}$ & $10^{3}$ & $10^{4}$ & $5.10^{4}$ \\
\hline $\mathrm{Nu}$ in [present work] & 1.081 & 1.985 & 2.978 \\
\hline $\mathrm{Nu}$ in [25] & 1.109 & 2.004 & 3.031 \\
\hline
\end{tabular}

Moreover, an analytical model was resolved to determine the ortho-radial velocity in steady state when $\mathrm{f}=0.5$ and $\mathrm{W}=10^{3}$. To simplify the analytical resolution, we consider the azimuthal symmetry and we supposed that the gravity forces are neglected. Then, the resolution of the second momentum equation written in cylindrical coordinates system, the orthoradial velocity is expressed as follows:

$u_{t}=\frac{\Omega}{R_{e x}^{2}-R_{i n}^{2}}\left(\frac{R_{e x}^{2} R_{i n}^{2}}{r}-R_{i n}^{2}, r\right)$

The evolution of the ratio $\mathrm{u}_{\mathrm{t}} / \mathrm{U}_{0}$ in the annular space calculated using Eq.10 is compared with the evolution estimated using COMSOL Multiphysics ${ }^{\circledR}$ in Fig.3. Overall, very good agreement is seen between analytical model and numerical analysis.

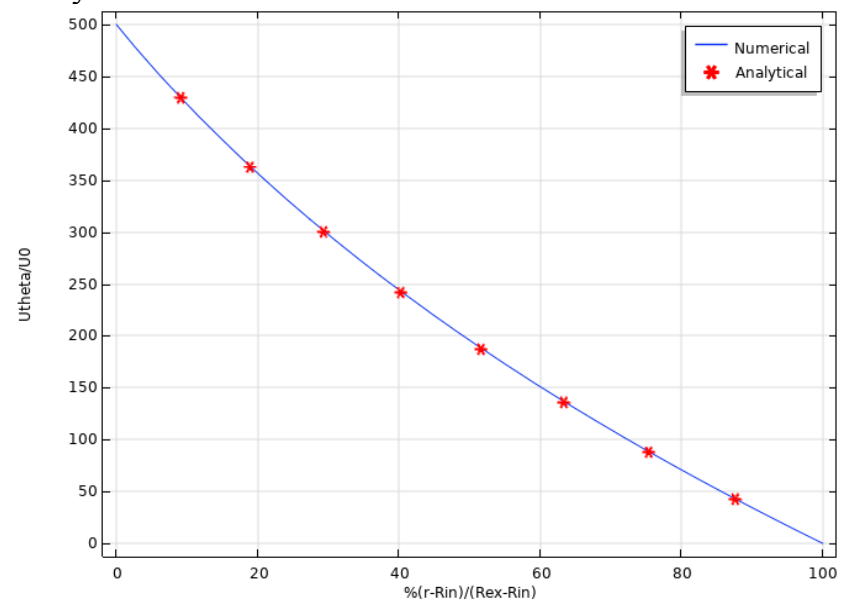

Figure 3 Validation with analytical model

Accordingly, we validated that the numerical model used in this work could correctly simulate natural convection in couette flow.

\section{Results and Discussions}

\subsection{Local distributions for different Ra}

Fig.4 illustrates the variation of local distributions of dimensionless temperature Fig.4(a), dimensionless velocity Fig.4 (b). Fig.5 shows dimensionless pressure Fig.5(a), and local Nusselt numbers Fig.5(b) for three different Rayleigh numbers. At low Rayleigh number $\mathrm{Ra}=10^{3}$, the movement of fluid particles and their propagation in the domain are mainly governed by viscous forces (the rotation of the hot cylinder).

On approaching the outer cylinder which is kept at a cold temperature, the fluid particles are immobile due to a zero temperature gradient in this region. The heat transfer then takes place only by conduction. In addition, we notice the presence of an immobile fluid cell straight ahead, which contributes to the braking of heat transfer: In fact, all of the flow turns to the left, and the speed to the right is almost absent. This reflects the low values of Nusselt numbers. By increasing the Rayleigh number $\mathrm{Ra}=10^{4}$, the movement of the fluid particles is attenuated. Two counter-rotating and asymmetrical cells appear. The hot fluid rises upwards in an ascending thermal plume. The temperature gradients are therefore low just above the inner cylinder, which explains the low Nusselt number values in this region $(\mathrm{Nu}$ int $)$. Above the hot cylinder, the fluid no longer follows the rotation of the cylinder and rather rises upwards until it reaches the cold cylinder.

On meeting the cold cylinder at the top of the annular space, the velocity of the hot fluid is low since the pressure is very high in this region. The strong temperature gradient then reflects the increase in heat transfer. Indeed, we notice an increase of $\mathrm{Nu}$ _ext in this region from $\mathrm{Ra}=10^{3}$ to $\mathrm{Ra}=10^{4}$.

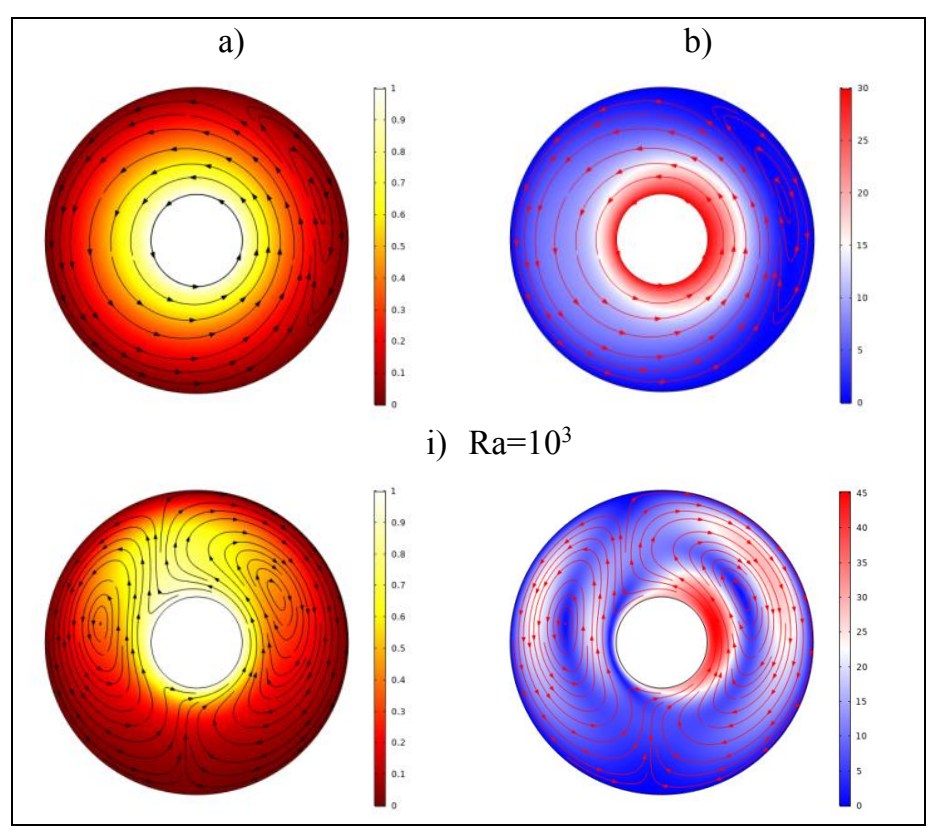




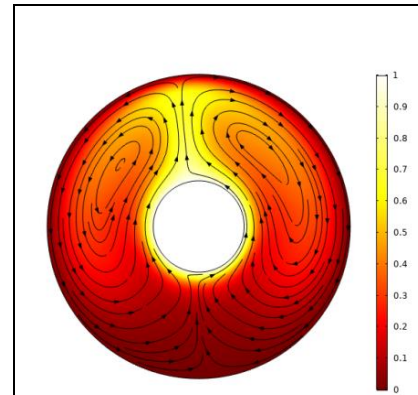

ii) $\mathrm{Ra}=10^{4}$

iii) $\mathrm{Ra}=10^{5}$

Figure 4 a)Local dimensionless temperature, b)Local dimensionless velocity for different $\mathrm{Ra}$

In addition, the temperature gradients are higher on the right side of the hot cylinder. This reflects the rise in the Nusselt number $\mathrm{Nu}_{\text {int }}$ on the right side more than on the left side. Eventually, the fluid particles are almost immobile at the lower part of the annular space and cause poor heat transfer in this

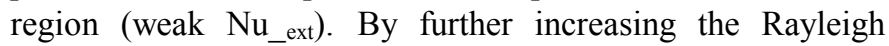
number $\mathrm{Ra}=10^{5}$, the fluid flow increases in speed, following two counter-rotating rollers that are slightly dissymmetrical. The speeds are always very low in the lower part of the annular space. The high pressures are localized at the top of the annular space, and limit the speed of the flow in this area. In addition, an ascending thermal plume above the hot inner cylinder due to the effect of the difference in the density of the fluid. This shows that the flow is no longer dependent on inner cylinder rotation, and that the buoyancy forces have dominated the viscosity forces and have started to monopolize the flow structure. The movement of fluid particles tends to a more stable state and approaches the phenomenon of natural convection between two motionless cylinders. This leads to an improvement in the heat transfer on the inner cylinder where we notice that the distribution of $\mathrm{Nu}_{-}$in is practically symmetrical going from $\mathrm{Ra}=10^{4}$ to $\mathrm{Ra}=10^{5}$. Regarding the heat transfer at the outer cylinder, we notice that the elongation of $\mathrm{Nu}_{-}$ext is strongly related to the Rayleigh number. Indeed, $\mathrm{Nu}_{\text {ext }}$ takes its maximum value at the top of the annular space where the temperature gradients are very high.

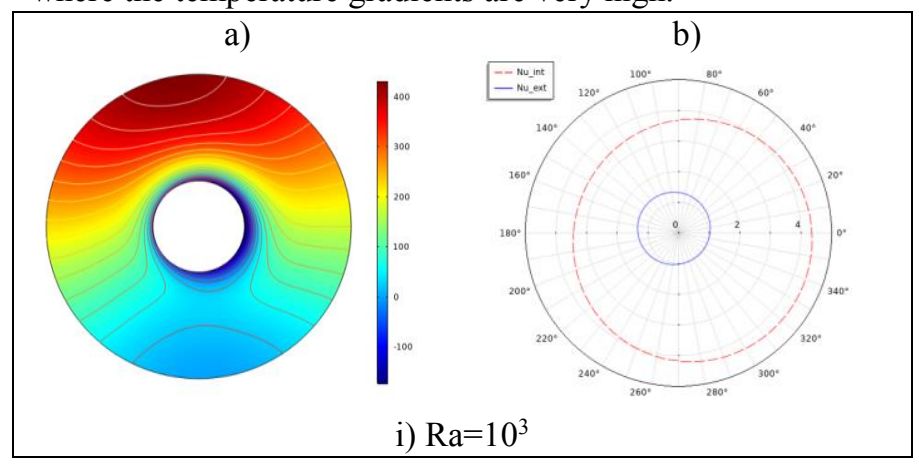

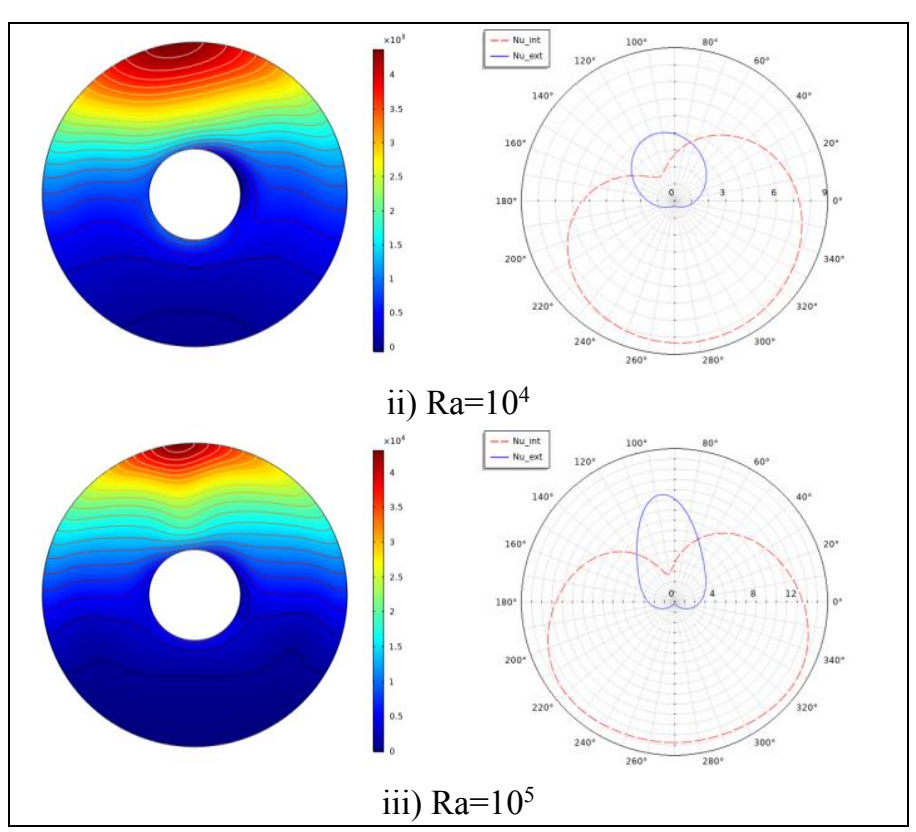

Figure 5 a)Local dimensionless pressure, b)Local Nusselt numbers for different $\mathrm{Ra}$

\subsection{Local distributions for different $W$}

Local distributions of temperature, velocity, pressure and Nusselt numbers are depicted, respectively, in Fig.6 and Fig.7 for different $\mathrm{W}$. For $\mathrm{W}=10^{2}$, the movement of fluid particles is governed by viscous and buoyancy forces. Fluid flow follows two asymmetric counter rotating rollers. At the top of the annular space, we notice that the flow velocity is slowed down due to the high pressures located in this area. This causes a low temperature gradient with the hot inner cylinder, which explains the low $\mathrm{Nu}_{-}$int values at the top of the hot cylinder.

An ascending thermal plume is also noticed which participates in the rise of the temperature gradient with the cold outer cylinder and promotes heat exchange. This explains the rise in $\mathrm{Nu}_{\text {ext }}$ in this region. In addition, the speed of the fluid particles is accentuated on the sides of the hot cylinder thanks to its rotation and it is maximum on the right side. This facilitates heat transfer and explains the high values of $\mathrm{Nu}_{-}$int on the sides. Likewise, the fluid is practically still in the lower part of annulus. Then, the heat remains blocked just below the hot cylinder. This leads to a strong temperature gradient in the vicinity of the inner cylinder and a weak gradient in the vicinity of the cold outer cylinder. This explains the high values of $\mathrm{Nu}_{-}$int and the low one of $\mathrm{Nu}_{\text {ext }}$ at the bottom part of the inner cylinder. 


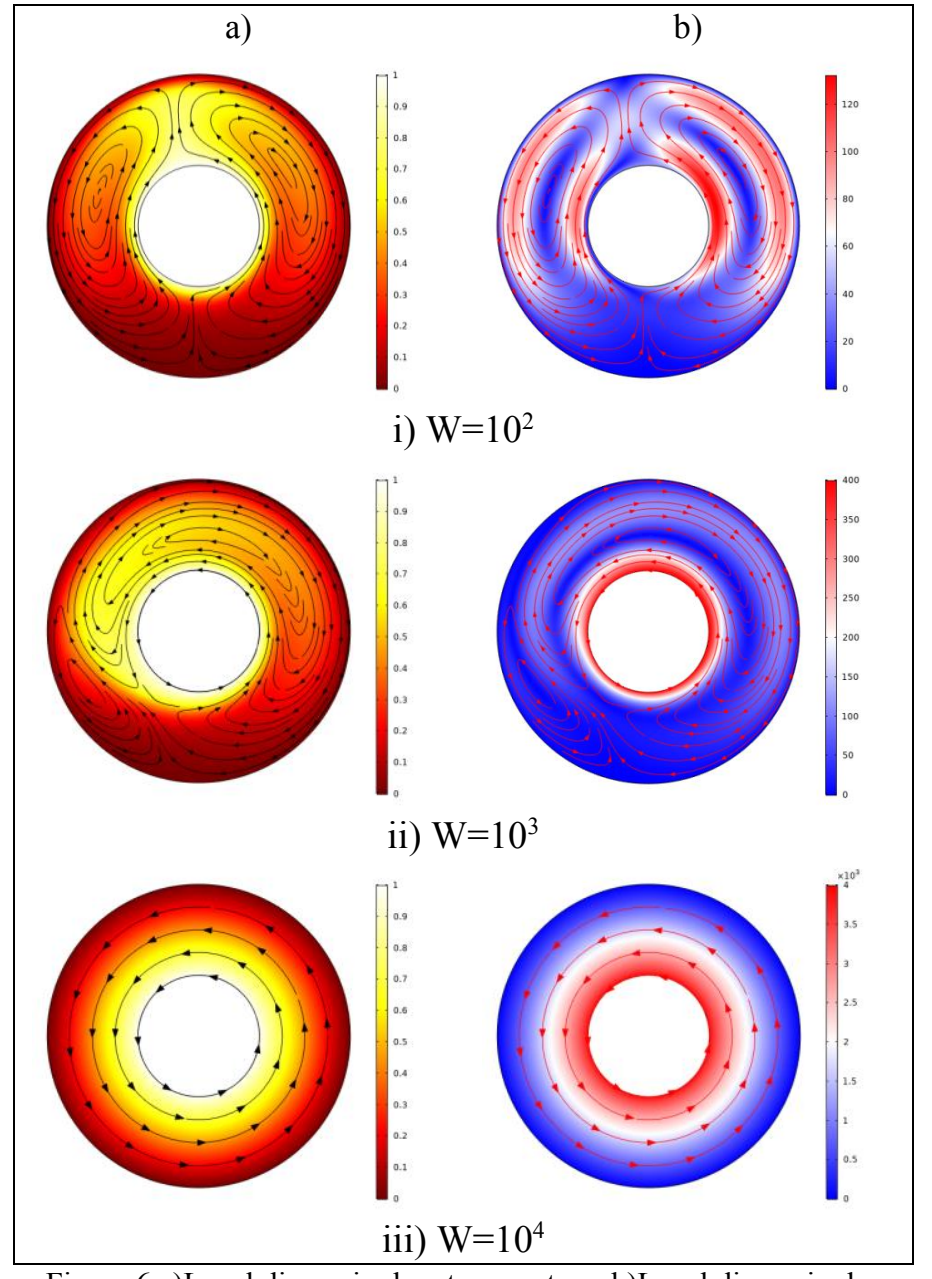

Figure 6 a)Local dimensionless temperature, b)Local dimensionless velocity for different $\mathrm{W}$

By increasing $\mathrm{W}$ to $10^{3}$, the speed of the fluid particles increases. The buoyancy forces weaken in front of those of viscosity, and cause a decrease in heat transfer rates $\left(\mathrm{Nu}_{\text {_int }}\right.$ and $\mathrm{Nu}_{\text {ext }}$ ). The fluid flow follows two counter-rotating cells: the right cell is dominant and the second on the left is practically motionless. The high pressure zone widens in the upper part of the annulus, thereby limiting the flow velocity in this region. The high speeds are therefore localized in the vicinity of the inner cylinder. The distribution of $\mathrm{Nu}_{\text {ext }}$ follows the locations of the strong temperature gradients between the fluid and the cold cylinder, located mainly in the left part of the annular space. As for the heat transfer rate with the hot cylinder, it is mainly located in the right part of the annular space where the temperature gradients are strong between the hot cylinder and the fluid.

By further increasing the speed of rotation of the inner cylinder $\mathrm{W}=10^{4}$, the pressure and speed of the flow are greatly accentuated in the annular space. Viscous forces are therefore dominant. This causes a drop in heat transfer rate, which becomes purely conductive.

\subsection{Local distributions for different $\mathbf{f}$}

Fig. 8 illustrates, for different $f$, the local distribution of adimensional temperature Fi.8 (a), dimensionless velocity Fig.8 (b). Fig.9 shows dimensionless pressure Fig.9 (a) and local Nusselt numbers Fig.9 (b). For $\mathrm{f}=0.2$, the fluid flow is asymmetrical, rises along a thermal plume deflected to the left, at which the heat transfer rate is limited (low value of $\mathrm{Nu}_{-}$int on the plume region).

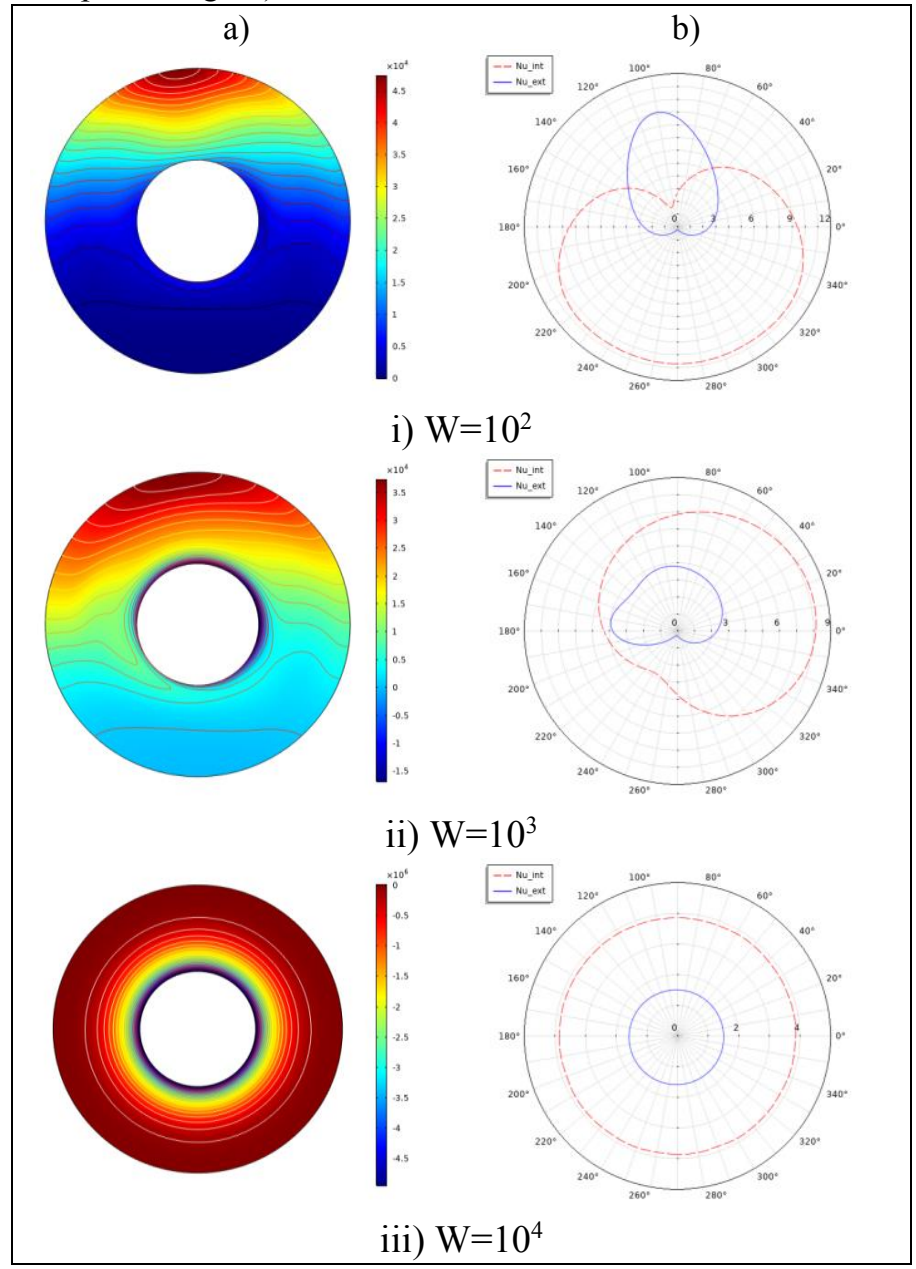

Figure 7 a)Local dimensionless pressure, b)Local Nusselt numbers for different $\mathrm{W}$

Upon meeting the high pressure area located in the upper left portion of the annular space, the fluid tends to follow the low pressure areas and divides into two counter-rotating cells. The right cell is dominant and generates high gradients between the hot cylinder and the fluid. This allows a higher thermal transfer and explains the high values of $\mathrm{Nu}_{-}$int in the right part. Furthermore, the distribution of $\mathrm{Nu}_{\text {_ext }}$ is strongly related to temperature gradients. Indeed, at the high-pressure zone, the temperature gradient between the fluid and the outer cylinder increases and promotes heat exchange $\left(\mathrm{Nu}_{-} \mathrm{ext}\right.$ is maximum). In the vicinity of the rest of the cold cylinder, the temperature gradient decreases, especially in the lower zone of the annular space where the fluid is almost immobile $\left(\mathrm{Nu}_{\text {e ext }}\right.$ is minimum).

For $\mathrm{f}=0.5$, the annular space decreases and causes a remarkable decrease in the rate of heat transfer since the hot 
fluid is blocked and does not find enough space to exchange heat. Viscous forces are becoming more and more preponderant. On the other hand, the movement of particles constitutes a dominant rotating roller in the annular space, and a motionless fluid zone in the lower left part. The velocity is highest just around the hot cylinder, and low elsewhere, as the high pressure zone spans the entire top of the annular space. One notices all the same that the lower part of the fluid field is always motionless.

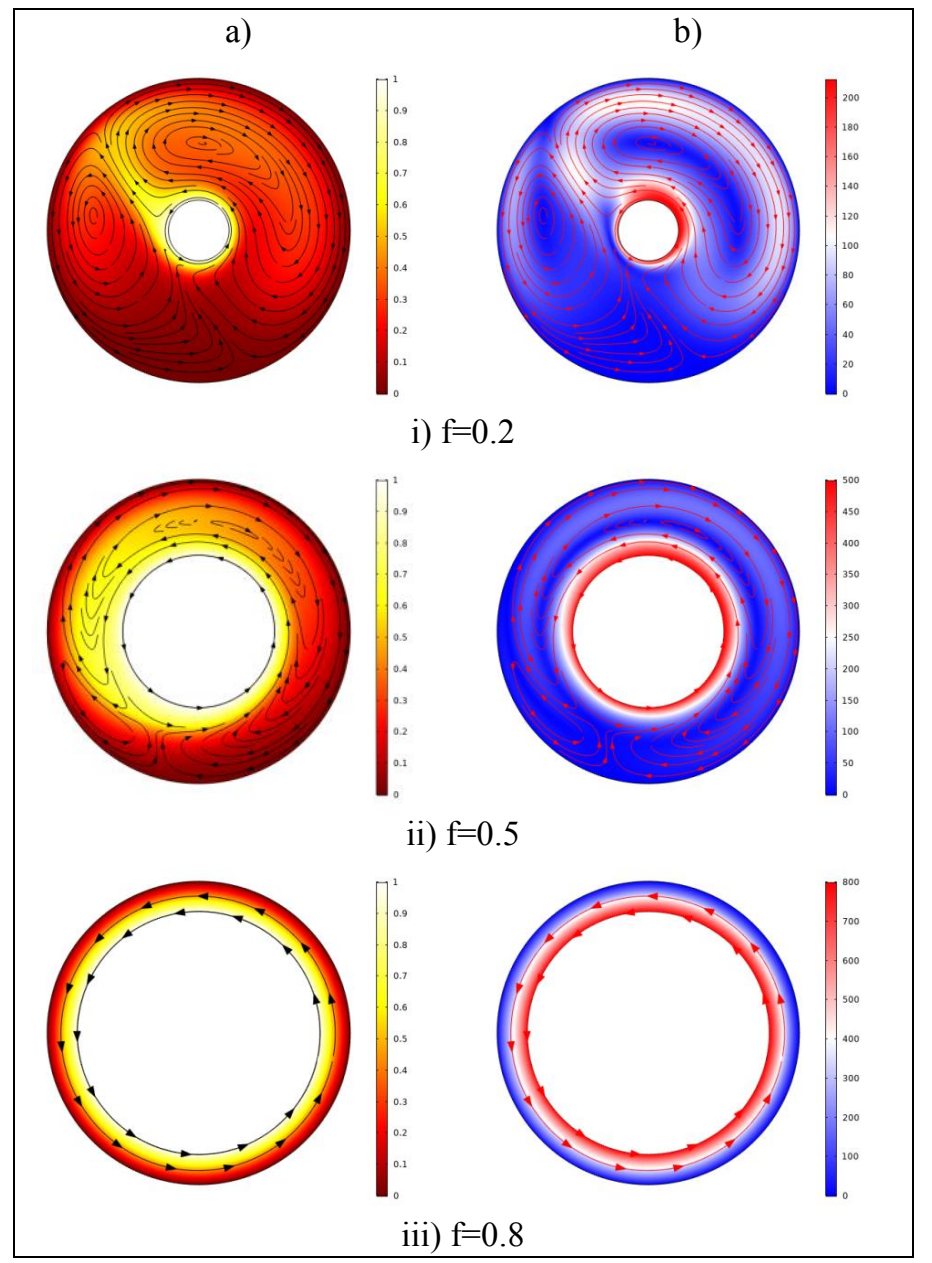

Figure 8 a)Local dimensionless temperature, b)Local dimensionless velocity for different $\mathrm{f}$

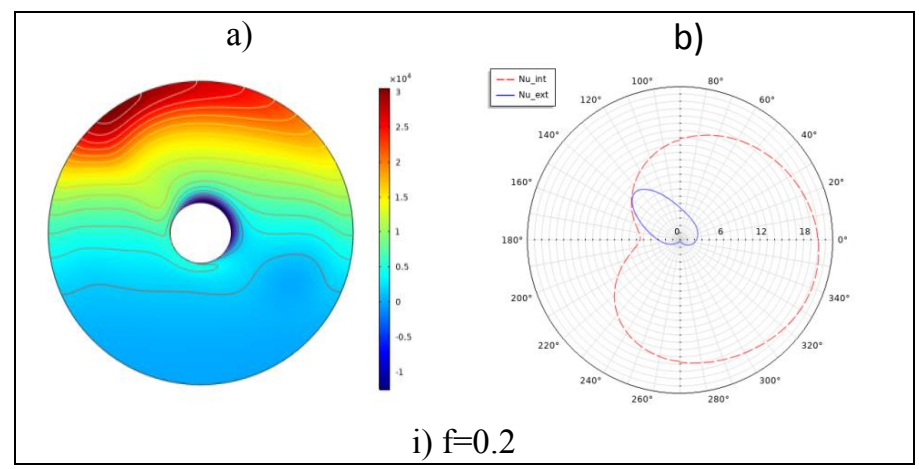

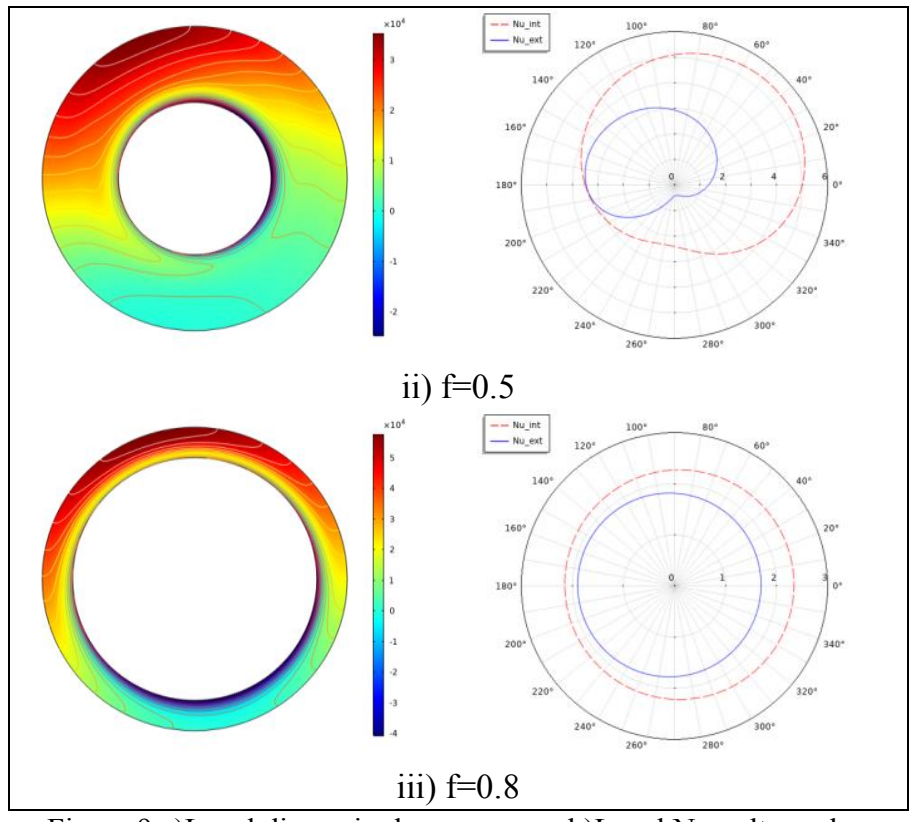

Figure 9 a)Local dimensionless pressure, b)Local Nusselt numbers for different $f$

In addition, the deflection of the hot fluid to the left causes high temperature gradients in the vicinity of the cold cylinder, which improves the rate of heat transfer in this part and explains the deformation of $\mathrm{Nu}_{\text {_ext. }}$. However, the heat exchange with the inner cylinder is favorable just to the left of the cylinder where the temperature gradients are important.

For $\mathrm{f}=0.8$, the buoyancy forces are no longer meaningful. The movement of the fluid is accelerated, and its pressure is very high in most of the area. Thus, the rotation of the particles follows a single rotating roller and the transfer appears to be only conductive. As a result, the transfer rate slows down as the annular space narrows so as to block hot fluid in the vicinity of the inner cylinder and prevent heat exchange. For this reason, the values of $\mathrm{Nu}_{\text {int }}$ and $\mathrm{Nu}_{\text {e ext }}$ have dropped.

\subsection{Effect of Rayleigh number}

As depicted in Fig.10, the mean dimensionless temperature decreases when the Rayleigh increases for the different cases

studied. We notice that the increase in the radius ratio $f$ causesan increase in the mean dimensionless temperature since the exchange surface decreases and the fluid does not find enough space to exchange heat. This leads to a decrease in heat transfer rate and subsequently to an increase in the average temperature of the fluid. Likewise, the increase in the speed of rotation causes a drop in the heat transfer rate because the hot fluid remains blocked in the vicinity of the hot cylinder. This results in an increase in the mean dimensionless temperature. 


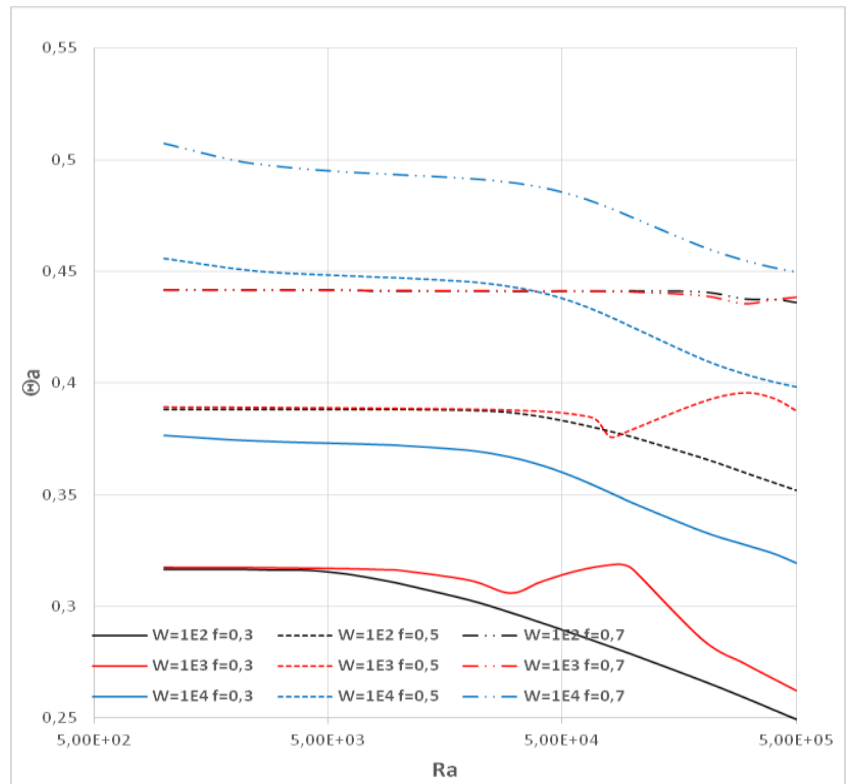

Figure 10 Effect of Rayleigh number on the adimensional temperature

The effect of Rayleigh number on the mean dimensionless velocity illustrated in Fig. 11 is minimal. Indeed, for $\mathrm{W}=10^{2}$, and $\mathrm{W}=10^{3}, \mathrm{U}_{\mathrm{a}}$ is almost constant as a function of Rayleigh number for the different radius ratios studied. On the other hand, for $\mathrm{W}=10^{4}$, the speed remains constant as we increase $\mathrm{Ra}$, and it starts to drop from $\mathrm{Ra}=5.10^{4}$.

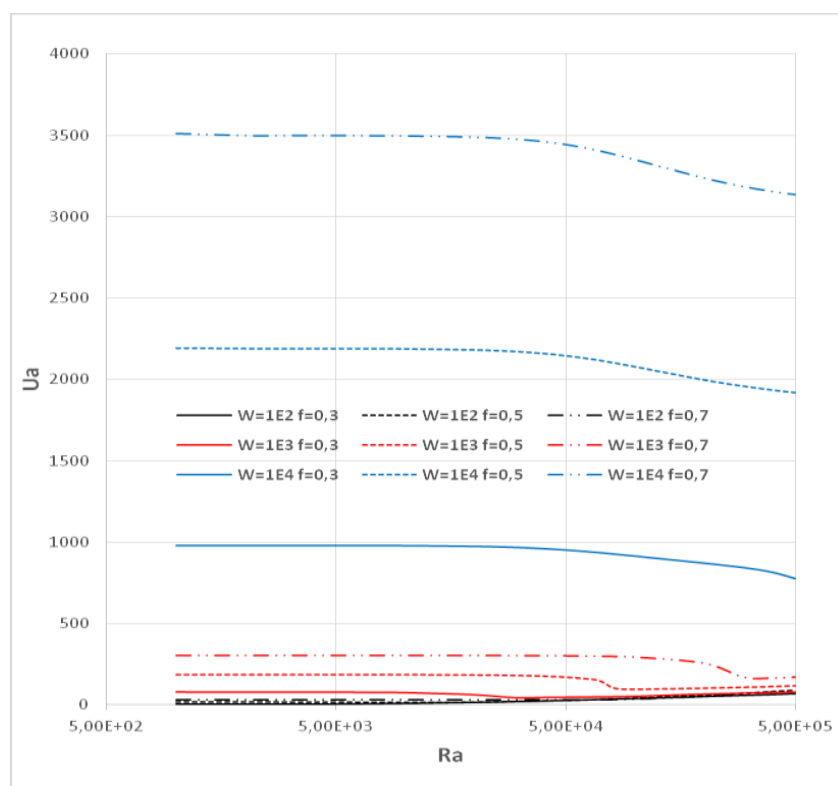

Figure 11 Effect of Rayleigh number on the adimensional velocity

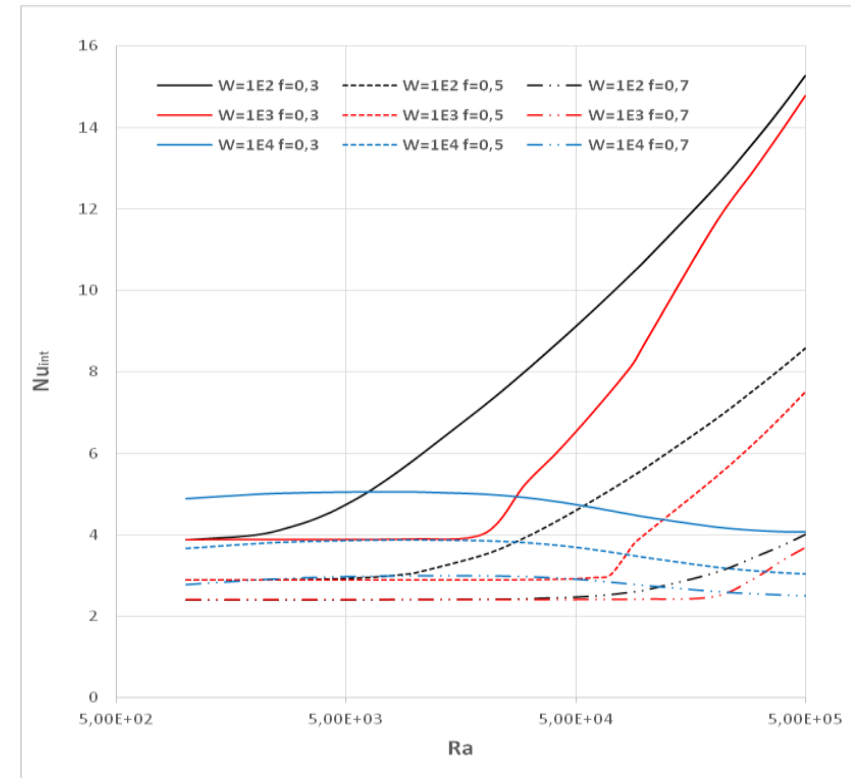

Figure 12 Effect of Rayleigh number on the mean Nusselt number

The Nusselt number is strongly related to the Rayleigh as depicted in Fig.12. Indeed, the heat transfer rate is more important when the Rayleigh is higher thanks to the improvement of the buoyancy forces.

However, for higher rotational speeds $\left(\mathrm{W}=10^{4}\right)$, it is noted that the Nusslet number remains practically stable as a function of Rayleigh. This is because of the dominance of viscosity forces which slow down heat transfer.

In addition, the Nusselt weakens with increasing the radius ratio $f$, since the rate of heat exchange is proportional to the exchange surface.

Regarding energy efficiency illustrated in Fig.13, we notice that, for $\mathrm{W}=10^{2}, \mathrm{~W}=10^{3}$, the energy efficiency is maximum with $\mathrm{Ra}=10^{3}$, and it is minimum with $\mathrm{Ra}=10^{5}$. On the other hand, for the case $\mathrm{W}=10^{4}$, the maximum value of energy efficiency is reached with $\mathrm{Ra}=10^{5}$.

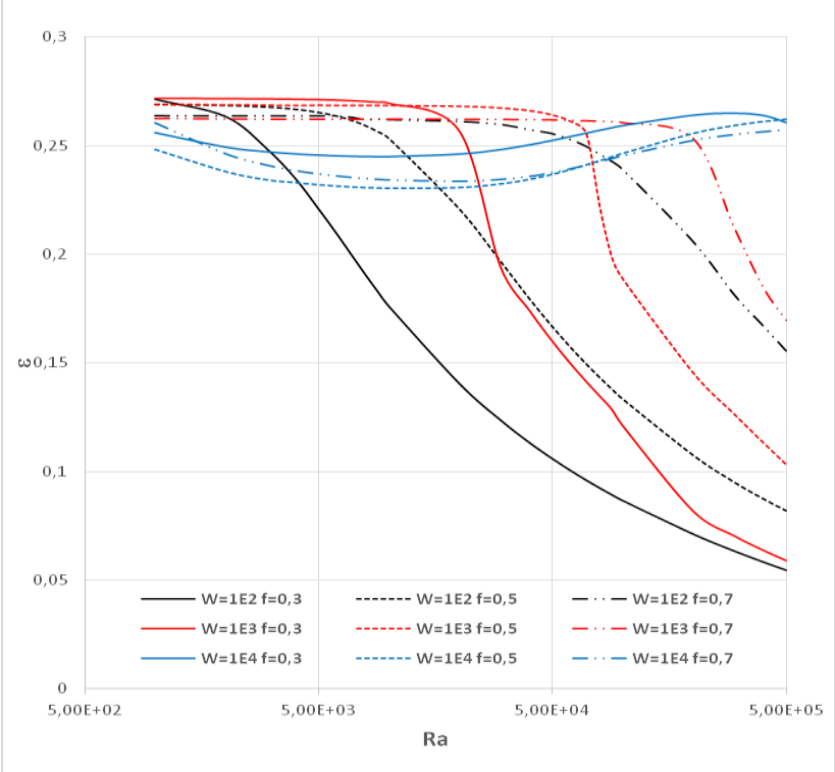

Figure 13 Effect of Rayleigh number on the energy efficiency 


\subsection{Effect of radius ratio}

The change in the mean dimensionless temperature as a function of the ratio $f$ is illustrated in Fig.14. It is clear that the dimensionless temperature increases by increasing $\mathrm{f}$. This is quite predictable since the exchange surface decreases and slows down the heat transfer between the two cylinders.

We also note that the dimensionless mean temperature decreases with the increase in Rayleigh number thanks to the improvement of the buoyancy forces which accelerate the heat exchange. Likewise, the dimensionless mean temperature rises as the rotation speed increases. This is because viscous forces become dominant as we increase $\mathrm{W}$. This slows the rate of heat transfer and causes an increase in the average dimensionless temperature.

From Fig.15, note that the effect of the increase of $f$ on the mean dimensionless velocity is only visible for high Rayleigh numbers: $\mathrm{Ra}=10^{5}$, where the speeds generated by the buoyancy forces become significant. On the other hand, the dimensionless mean velocity reaches its maximum values when the rotation speed is high $\mathrm{W}=10^{4}$.

We notice on Fig.16 that the Nusselt number is lower for higher radius ratios. Moreover, the Nusselt number is closely linked to the Rayleigh number. Indeed, $\mathrm{Nu}_{\text {int }}$ increases when $\mathrm{Ra}$ increases. Concerning the effect of the rotation speed, we notice that $\mathrm{Nu}_{\text {int }}$ decreases by increasing w. This is because of the hot fluid blocked around the outer cylinder. This leads to a reduction in heat exchanges and results in a reduction in $\mathrm{Nu}_{\text {int }}$.

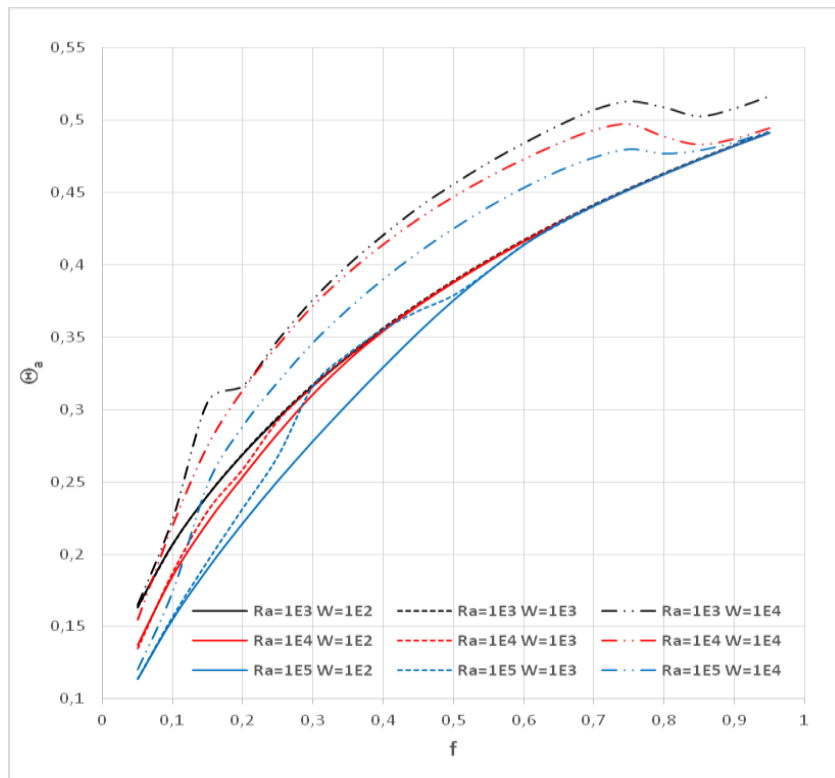

Figure 14 Effect of radius ratio on the adimensional temperature

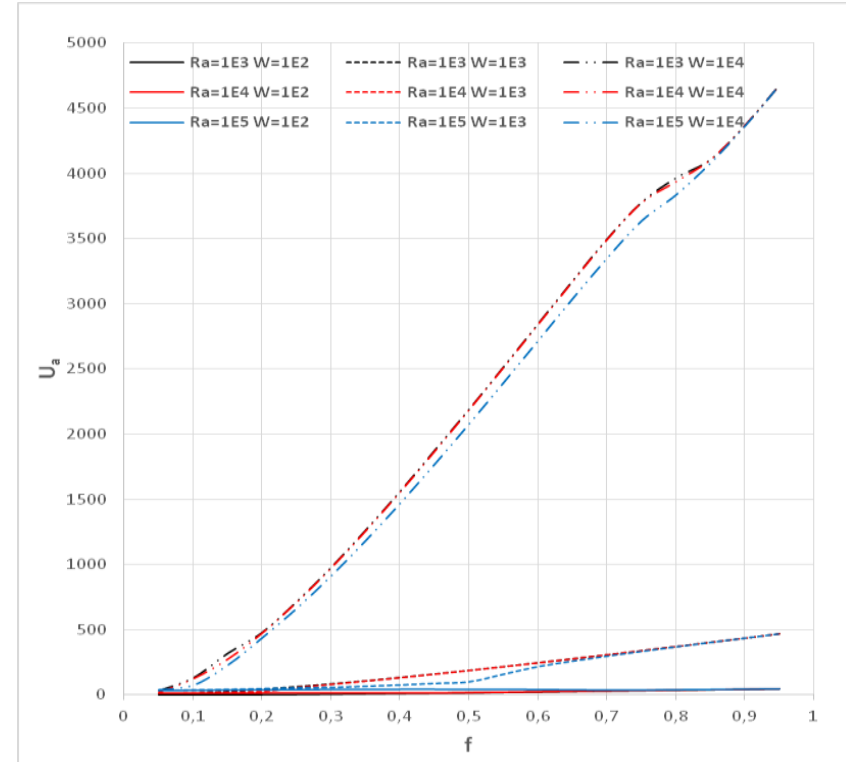

Figure 15 Effect of radius ratio on the adimensional velocity

Fig. 17 illustrates the effect of $f$ on the energy efficiency. We note, regardless of the rotational speed and $\mathrm{Ra}$ imposed, the energy efficiency is amplified with the increase of $f$, until reaching a constant value for high radius ratios ( $f>0.8$ ). In addition, the efficiency improves with increasing $\mathrm{W}$, but it becomes stable at high $\mathrm{f}$. However, the efficiency decreases as the Rayleigh number is increased.

For the case $\mathrm{Ra}=10^{3}, \mathrm{~W}=10^{4}$, we notice an instability of energy efficiency, due to non-stationarity of the flow.

\subsection{Effect of rotational velocity}

The effect of the rotation speed on the dimensionless mean temperature is illustrated in Fig.18. We note an increase with increasing $f$ because the annular space narrows and causes a reduction in the amount of heat exchanged. In contrast, the dimensionless mean temperature decreases with increasing $\mathrm{Ra}$ since the buoyancy forces become large and promote heat exchange. 


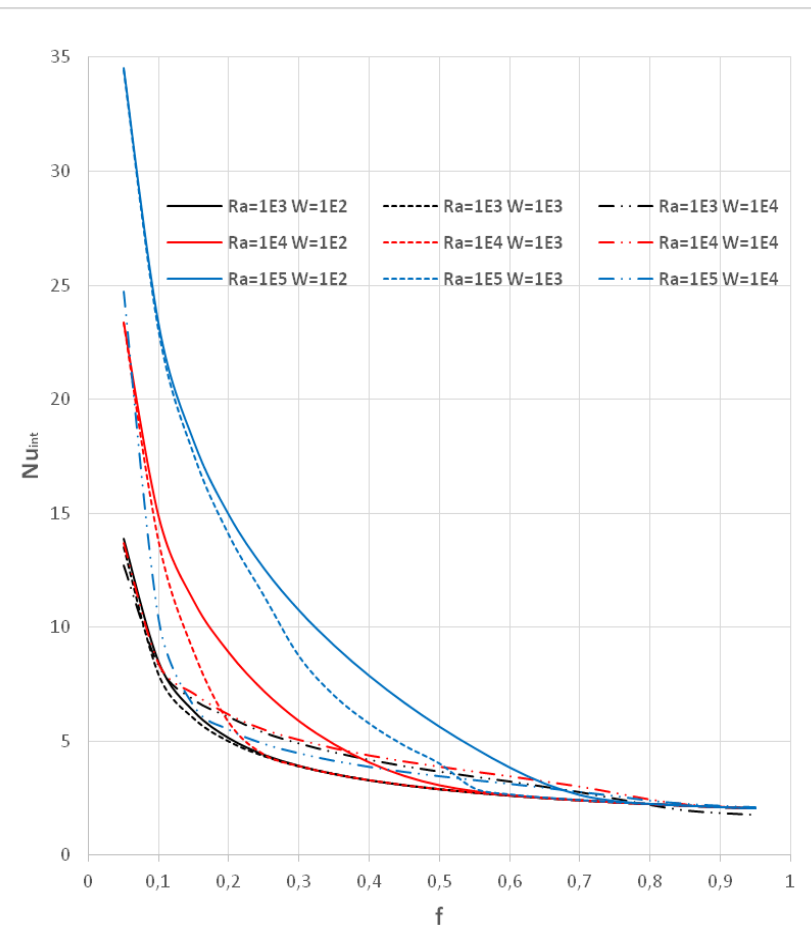

Figure 16 Effect of radius ratio on the mean Nusselt number

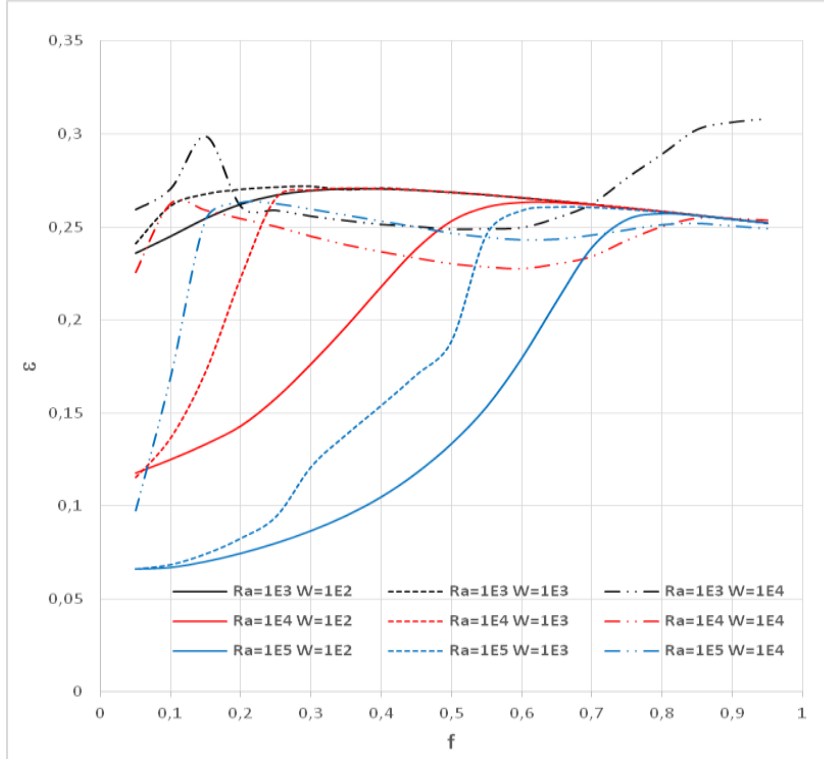

Figure 17 Effect of radius ratio on the energy efficiency

However, the effect of the rotational speed $\mathrm{w}$ is not remarkable only for large radius ratios $(\mathrm{f}=0.7)$ because in this case the annular space is small and the fluid motion is totally dependent on the speed of rotation whatever its value.

For $\mathrm{f}=0.3$ and $\mathrm{f}=0.5$, we notice that the effect of the rotational speed is mainly remarkable for $\mathrm{Ra}=10^{5}$ when the buoyancy forces become important. There is an increase in the mean dimensionless temperature with increasing rotational speed. This is quite predictable because the hot fluid gets stuck in the vicinity of the hot cylinder, which limits the rate of heat transfer and produces an increase in the average dimensionless temperature of the fluid.

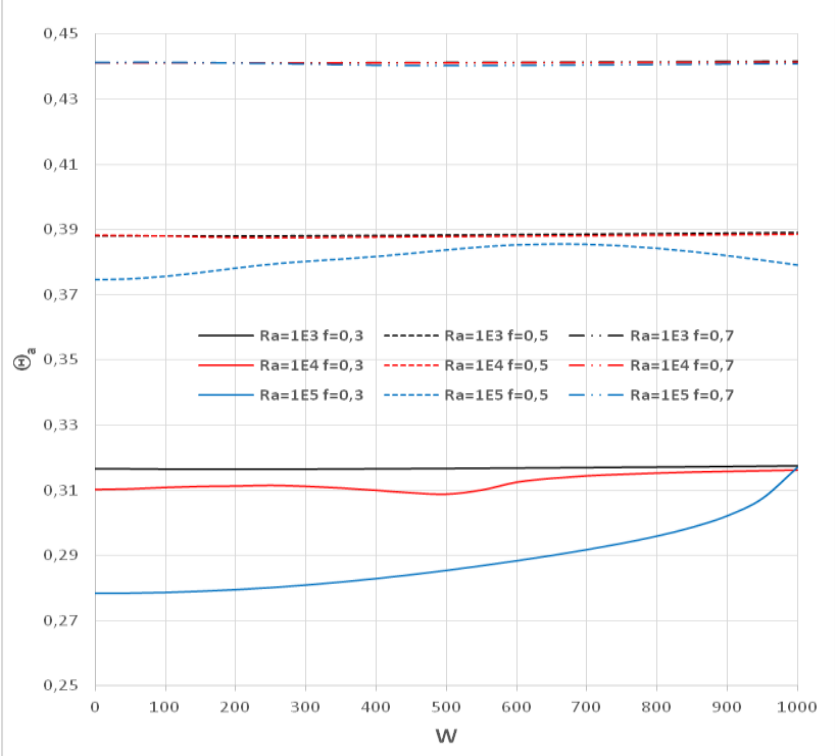

Figure 18 Effect of rotation velocity on the adimensional temperature

Concerning the dimensionless velocity, it is obvious that it is proportional to the rotation speed of the hot fluid. Moreover, as shown in Fig.19, it is clearly related to the radius ratio f. Indeed, with reduced annular spaces, the fluid is driven by the rotation of the hot cylinder.

On the other hand, the dimensionless mean velocity decreases by increasing the Rayleigh number, since the buoyancy forces become important with high Rayleigh numbers.

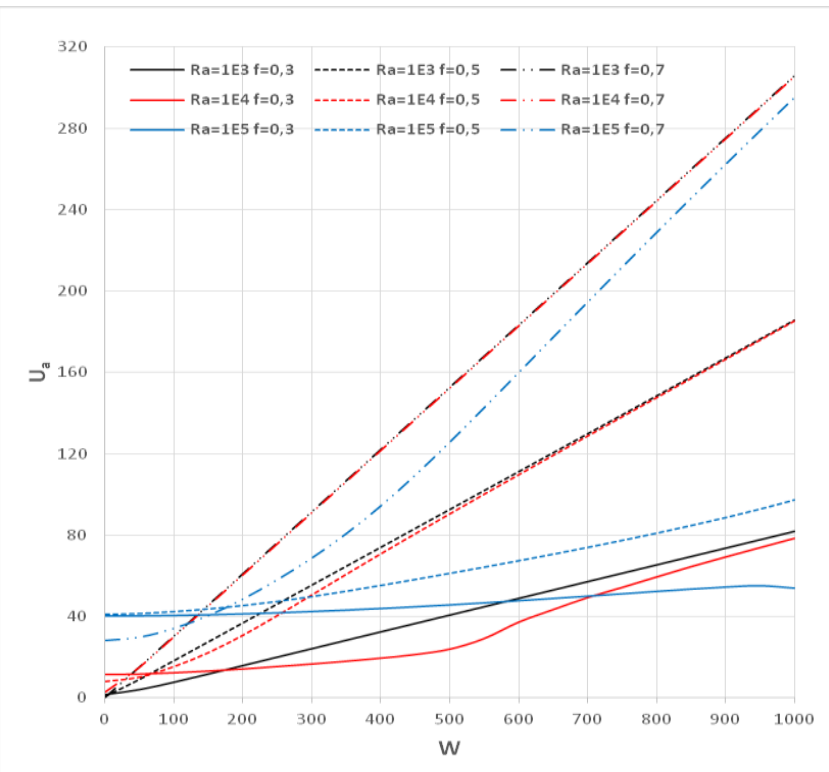

Figure 19 Effect of rotation velocity on the adimensional velocity

Since the Nusselt number is related to the Rayleigh, then it is obvious that it increases by increasing $\mathrm{Ra}$ as shown in Fig.20. Moreover, we notice for $\mathrm{f}=0.3$ and $\mathrm{Ra}=10^{5}$, the Nusselt number is maximal. On the other hand, the effect of the increase in the rotation speed on the heat transfer rate is very 
weak for low Rayleigh numbers $\left(\mathrm{Ra}=10^{3}\right.$, because the transfer is done purely by conduction), and for ratios of high radius ratios ( $\mathrm{f}=0.7$, because the exchange surface decreases very much). This is why the Nusselt number remains practically constant. On the other hand, the Nusselt decrease with increasing rotational speed can be explained by the fact that viscosity forces become dominant and slow down the rate of heat exchange.

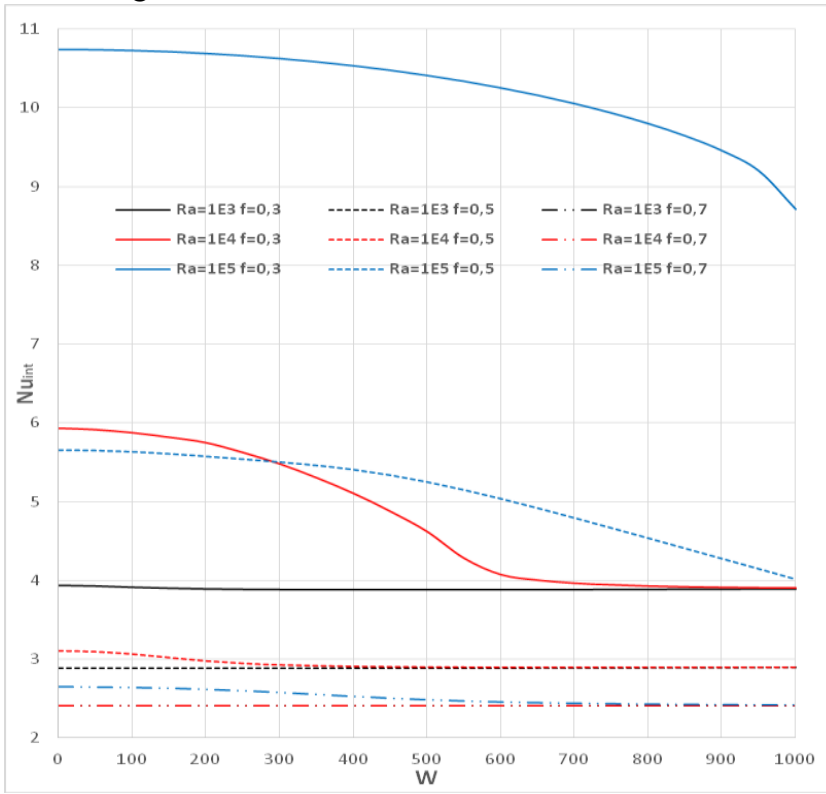

Figure 20 Effect of rotation velocity on the mean Nusselt number

The effect of the rotation velocity on the energy efficiency is shown in Fig.21. Note that the effect is not visible for $\mathrm{Ra}=$ $10^{3}$, because the buoyancy forces are negligible compared to those of viscosity, and for $\mathrm{f}=0.7$ because the exchange surface is small. In contrast, energy efficiency improves by increasing the Rayleigh number through the amplification of the buoyancy forces. The increase in energy efficiency is exponential for $\mathrm{Ra}=10^{5}$, while for $\mathrm{Ra}=10^{4}$ it stabilizes when reaching high rotational speeds.

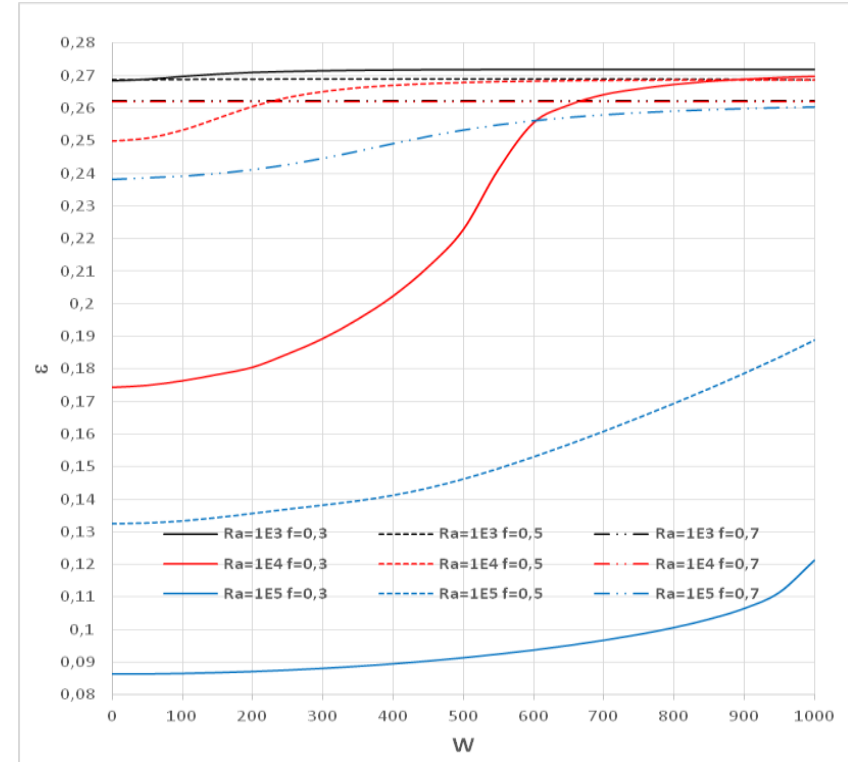

Figure 21 Effect of rotation velocity on the energy efficiency

\section{Conclusion}

In this work, we have developed a numerical study of natural convection between two horizontal coaxial cylinders. The inner one is hot and rotates. However the outer cylinder is cold and motionless. The adimensional study proved that Rayleigh number, the radius ratio $f$ and the rotation speed of the inner cylinder have remarkable effects on the natural convection behavior. In fact, we have demonstrated that buoyancy forces are ameliorated when increasing Rayleigh number. This leads to an increase of the heat exchange in the annular space. However, the heat transfer rate decreases with the increase of the radius ratio $f$, since the exchange surface narrows. It have been also demonstrated that for higher rotation speeds, the hot fluid is blocked in the vicinity of the outer cylinder, resulting in a decrease of the heat transfer rate. Finally, the energy efficiency is found to be maximum in the case of both low Rayleigh number $\mathrm{Ra}=10^{3}$ (since the buoyancy forces are weak) and low rotation speed. Future work will concern the effect of the inner cylinder position to explore its effects on the natural convection behavior and on the energy efficiency level.

Nomenclature

\begin{tabular}{|cl|}
\hline$g$ & acceleration due to gravity $\left[\mathrm{m} \cdot \mathrm{s}^{-2}\right]$ \\
$N u$ & Nusselt number \\
$P$ & pressure $[\mathrm{Pa}]$ \\
$P r$ & Prandtl number \\
$R$ & cylinder radius $[\mathrm{m}]$ \\
$R a$ & Rayleigh number \\
$(r, \phi)$ & cylindrical coordinate system \\
$T$ & Temperature $[\mathrm{K}]$ \\
$\Delta T$ & temperature difference, $T_{\mathrm{h}}-T_{\mathrm{c}}[\mathrm{K}]$ \\
$(U, V)$ & dimensionless velocity components \\
$(u, v)$ & velocity components $\left[\mathrm{m} \cdot \mathrm{s}^{-1}\right]$ \\
\hline
\end{tabular}




\begin{tabular}{|cl|}
\hline $\mathrm{W}$ & dimensionless angular velocity \\
$(X, Y)$ & dimensionless Cartesian coordinates \\
$(x, y)$ & Cartesian coordinates \\
Greek Symbols \\
$\alpha$ & thermal diffusivity $\left[\mathrm{m}^{2} \cdot \mathrm{s}^{-1}\right]$ \\
$\beta$ & thermal expansion coefficient $\left[\mathrm{K}^{-1}\right]$ \\
$\varepsilon$ & energy efficiency \\
$\Theta$ & dimensionless temperature \\
$v$ & kinematic viscosity $\left[\mathrm{m}^{2} \cdot \mathrm{s}^{-1}\right]$ \\
$\Pi$ & dimensionless pressure \\
$\rho$ & density $\left[\mathrm{kg} \cdot \mathrm{m}^{-3}\right]$ \\
$\Omega$ & Angular velocity $\left[\mathrm{rad}^{-1} \mathrm{~s}^{-1}\right]$ \\
Subscripts & \\
$\mathrm{a}$ & average \\
$\mathrm{c}$ & cold \\
$\mathrm{h}$ & hot \\
int & inner \\
ext & outer \\
\hline
\end{tabular}

\section{References}

[1] F. Tachibana, S. Fukui, H. Mitsumura, "Heat transfer in an annulus with an inner rotating cylinder". Bulletin of JSME 3 (9), (1960), pp. 119-123. https://doi.org/10.1299/jsme1958.3.119

[2] F. Tachibana, S. Fukui, "Convective heat transfer of the rotational and axial flow between two concentric cylinders", Bulletin of JSME 7 (26), (1964), pp. 385-391 https://doi.org/10.1299/jsme1958.7.385

[3] C. D. Andereck, S. Liu, H. L. Swinney), "Flow regimes in a circular couette system with independent rotating cylinders", Journal of Fluid Mechanics 164, (1986), pp.155-183. http://dx.doi.org/10.1017/S0022112086002513

[4] R.E. Powe, C.T. Carley, E.H. Bishop, "Free convective flow patterns in cylindrical annuli", J. Heat Transfer 91, (1969), pp. 310-314. https://doi.org/10.1115/1.3580158

[5] T. H. Kuehn and R. J. Goldstein, "An experimental and theoretical study of natural convection in the annulus between horizontal concentric cylinders", J. Fluid Mech. 74, (1976), pp. 695-719. https://doi.org/10.1017/S002211207600201

[6] T. H. Kuehn and R. J. Goldstein, "A parametric study of Prandtl number and diameter ratio effects on natural convection heat transfer in horizontal cylindrical annuli", J. Heat Transfer 102, (1980), pp. 768-770. https://doi.org/10.1115/1.3244388

[7] J. R. Custer and E. J., "Shaughnessy Thermoconvective motion of low Prandtl number fluids within a horizontal cylindrical annulus", J. Heat Transfer 99, (1977), pp. 596601.

https://doi.org/10.1115/1.3450748

[8] Yoo, J.S., "Natural convection in a narrow horizontal cylindrical annulus: $\operatorname{Pr}<0.3$ ", Int. J. Heat Mass Transfer 41, (1998), pp. 3055-3073.
https://doi.org/10.1016/S0017-9310(98)00051-9

[9] M. C. Charrier-Mojtabi, A. Mojtabi and J. P. Caltagirone, "Numerical solution of a flow due to natural convection in horizontal cylindrical annulus", J. Heat Transfer 101, (1979), pp.171-173.

https://doi.org/10.1115/1.3450911

[10] M. C. Jischke and M. Farshchi, “ Boundary layer regime for laminar free convection between horizontal circular cylinders", J. Heat Transfer 102, (1980), pp. 228-235. https://doi.org/10.1115/1.3244265

[11] Y. Rao, Y. Miki, K. Fukuda, Y. Takata, S. Hasegawa, “ Flow patterns of natural convection in horizontal cylindrical annuli”. Int.J. Heat Mass Transfer 28, (1985), pp.705-714. https://doi.org/10.1016/0017-9310(85)90193-0

[12] B. Farouk and S. I. Guceri, "Laminar and turbulent natural convection in the annulus between horizontal concentric cylinders", J. Heat Transfer 104, (1982), pp. 631-636. https://doi.org/10.1115/1.3245178

[13] S. Grossmann, D. Lohse, C. Sun, "High Reynolds number taylor-couette turbulence", Annual Review of Fluid Mechanics 48, (2016), pp.53-80. https://doi.org/10.1146/annurev-fluid-122414-034353

[14] Cheddadi, A., Caltagirone, J.P., Mojtabi A, Vafai, K, "Free two dimensional convective bifurcation in a horizontal annulus". J. Heat Transfer 114, (1992), pp.99106.

https://doi.org/10.1115/1.2911274

[15] G. Desrayaud, G. Lauriat, "Radiative influence on the stability of fluids enclosed in vertical cavities". Int. J. Heat Mass Transfer 31, (1988), pp.1035-1048. https://doi.org/10.1016/0017-9310(88)90092-0

[16]T.S. Lee, "Numerical Experiments with laminar fluid convection between concentric and eccentric heated rotating cylinder", Numerical Heat Transfer 7, (1984), pp.77-87.

https://doi.org/10.1080/01495728408961812

[17] T.S Lee, "Numerical computation of fluid convection with air enclosed between the annuli of eccentric heated horizontal rotating cylinders", Computers Fluids 21 (3), (1992), pp.355-368. https://doi.org/10.1016/0045-7930(92)90044-V

[18] S.C. Tzeng, "Heat transfer in a small gap between co-axial rotating cylinders", Int. Com. in Heat and Mass Transfer 33, (2006), pp.737-743

https://doi.org/10.1016/j.icheatmasstransfer.2006.02.012

[19] Joo-Sik Yoo, "Dual free-convective flows in a horizontal annulus with a constant heat flux wall". International Journal of Heat and Mass Transfer 46, (2003), pp. 24992503

https://doi.org/10.1016/S0017-9310(02)00539-2

[20] R.Hosseini, M.R.Heyrani-Nobari, M.Hatam, “An experimental study of heat transfer in an open-ended vertical eccentric annulus with insulated and constant heat flux boundaries". Applied Thermal Engineering 25, (2005), pp.1247-1257 https://doi.org/10.1016/j.applthermaleng.2004.08.016 
[21] Abiodun O. Ajibade and Yusuf A. Bichi, "Variable fluid properties and thermal radiation effects on natural convection couette flow through a vertical porous

Channel", Journal of Advances in Mathematics and Computer Science 31(1), (2019), pp.1-17. https://doi.org/10.9734/jamcs/2019/v31i130100

[22] Yusuf A. Bichi. and Ajibade, A.O., "Combined effects of variable viscosity, viscous dissipation and thermal radiation on unsteady natural convection Couette flow through a vertical porous channel", FUDMA Journal of Sciences (FJS) Vol. 4 No. 2, (2020), pp. 135 - 150. https://doi.org/10.33003/fjs-2020-0402-208

[23] M. R. H. Nobari a \& Ali Asgarian, "A Numerical Investigation of Flow and Mixed Convection Inside a Vertical Eccentric Annulus", Numerical Heat Transfer, Part A: Numerical Heat Transfer, Part A, 55, (2009), pp. 77-99.

https://doi.org/10.1080/10407780802603105

[24] N. Kline, S. Tavoularis, "An Experimental Study of Forced Heat Convection in Concentric and Eccentric Annular Channels", J. Heat Transfer, 138(1), (2016). https://doi.org/10.1115/1.4031160

[25] Desrayaud G., Lauriat G., Cadiou P. "Thermoconvective instabilities in a narrow horizontal air-filled annulus.", International Journal of Heat and Fluid Flow 21(1), (2000), pp.65-73.

https://doi.org/10.1016/S0142-727X(99)00048-X

\section{Creative Commons Attribution License 4.0 (Attribution 4.0 International, CC BY 4.0)}

This article is published under the terms of the Creative Commons Attribution License 4.0

https://creativecommons.org/licenses/by/4.0/deed.en_US 